\title{
Coeliac disease presenting with cerebellar degeneration
}

\author{
R.A. Hermaszewski, S. Rigby and A.G. Dalgleish \\ Northwick Park Hospital and Clinical Research Centre, Watford Road, Harrow HA1 3UJ, UK
}

\begin{abstract}
Summary: A case of rapidly progressive cerebellar degeneration with bilateral sixth nerve palsies is described in whom investigation revealed the presence of unsuspected coeliac disease. In spite of treatment with a gluten free diet, rapid fatal deterioration occurred. Coeliac disease should be considered in patients with encephalopathy of obscure origin.
\end{abstract}

\section{Introduction}

Coeliac disease is characterized by malabsorption, steatorrhoea, abdominal distension and flatulence together with weight loss. Neurological complications may occur in up to $10 \%$ of patients but in general are a secondary feature of the disease. Presented here is a patient with rapidly progressive cerebellar degeneration with biopsy evidence of coeliac disease in the absence of significant abdominal symptoms.

\section{Case report}

A 37 year old Asian man was referred following a 2-month history of progressive ataxia and bilateral sixth nerve palsy, accompanied by severe weight loss and anorexia. Five weeks prior to presentation he had noticed slurring of his speech, followed by weakness of his legs and progressive unsteadiness in walking. There was some blurring of vision and impairment of memory. Anorexia was accompanied by weight loss of approximately $15 \mathrm{~kg}$. He was opening his bowels twice daily but felt the stool was unchanged and normal. He denied previous neurological or gastrointestinal disease but had suffered a myocardial infarction 4 years previously which was complicated by angina after recovery, controlled with sublingual glyceryl trinitrate only. There was no family history of note and he had been resident in the UK since the age of 26 , working as a greengrocer, having last visited his native Pakistan 6 years prior to presentation.

The general examination was unremarkable

Correspondence: R. Hermaszewski, M.B., Ch.B., Department of Immunology, Northwick Park Hospital and Clinical Research Centre, Watford Road, Harrow HA1 3UJ, UK

Accepted: 2 May 1991 other than obvious recent loss of weight. Positive findings included bilateral sixth nerve palsies, other cranial nerves being normal, and cerebellar ataxia in all four limbs, which together with truncal ataxia made walking impossible without assistance. There was mild dysmetria, intention tremor and dysdiadochokinesia, more prominent on the right. His speech was cerebellar and rhythmical tremor of jaw and tongue was present. The limb reflexes were all brisk with poorly sustained ankle clonus but tone and power were normal. The plantar reflexes were not elicitable. All sensory modalities were intact. Ocular examination was normal, there was no nystagmus. He was alert and orientated with good short and long term memory.

Investigations at another hospital had included normal renal and liver function tests other than a raised alkaline phosphatase of $377 \mathrm{IU} / \mathrm{ml}$ (normal range 98-280). Calcium and phosphate were normal, as were thyroid function, vitamin $B_{12}$, glucose, and clotting screen. Full blood count and ESR were normal but the blood film showed occasional target cells. Red blood cell folate was $88 \mu \mathrm{g} / \mathrm{l}$ (normal 120-860) and he had been started on folate supplements. There was a weak positive titre for smooth muscle antibodies but other autoantibodies and serology to a panel of infective agents including human immunodeficiency virus were negative. Chest X-ray, computed tomographic (CT) scan of chest and abdomen and four vessel cranial arterial angiography were normal but a cerebral CT scan revealed cerebellar atrophy. Lumbar puncture revealed a protein of $0.82 \mathrm{~g} / 1$ with 4 red cells and 4 mononuclear cells per $\mathrm{mm}^{3}$ but no organisms. He was submitted for a bronchoscopy, which was normal, and a liver biopsy showed scanty non-specific inflammatory foci but no granulomata. On endoscopy, both duodenal and jejunal biposies revealed total villous atrophy with a plasma cell infiltrate in the lamina propria consistent with a diagnosis of coeliac disease. 
A gluten free diet was commenced together with oral doxycycline and metronidazole whilst awaiting microbiological results on small bowel aspirates, which proved negative. Relentless progression of his neurological lesions caused progressive ataxia and dysphasia together with urinary and faecal incontinence. Bronchopneumonia was followed by death 3 weeks after diagnosis. A limited autopsy revealed the immediate cause of death to be a myocardial infarction and confirmed the presence of coeliac disease. The central nervous system was macroscopically normal but was not examined histologically.

\section{Discussion}

The pathogenesis of this man's cerebellar and brain-stem degeneration is not clear. In the absence of supportive evidence for hereditary, inflammatory, toxic, metabolic or paraneoplastic causes it is tempting to speculate that the deterioration was a manifestation of his coeliac disease. A review of the literature reveals the presence of spinocerebellar degeneration in a handful of cases with established coeliac disease and this is a recognized, albeit rare, complication of malabsorption due to other causes such as inflammatory bowel disease or previous surgery. ${ }^{1-7}$ The lack of definite evidence of involvement of the spinal cord in this case may, in part, be due to masking of dorsal column symptoms by the profound cerebellar ataxia. In so far as cerebellạr symptoms are often the most prominent feature of coeliac disease associated encephalopathy this patient resembled reported cases. However, previously reported cases have often been patients who have had established coeliac disease for many years. ${ }^{1,5}$ The cerebellar degeneration is usually progressive but does not follow such a fulminant course as in this case. A very similar case, however, has previously been reported, in which the neurological manifestations of ataxia, dysarthria and internuclear ophthalmoplegia overshadowed the abdominal symptoms. The patient progressively deteriorated over 10 months prior to death due to pneumonia. ${ }^{2}$ Patchy cell loss was noted in the basal ganglia, nigral and olivary nuclei together with profound loss of Purkinje cells in the cerebellar folia and of neurones in the dentate nucleus. In the present case the premature death due to myocardial infarction may have served to shorten the apparent duration of the cerebellar degeneration.

The pathogenesis of degenerative neurological disease in adult coeliac disease is not known. Speculation has surrounded malabsorption of lipids with vitamin $\mathrm{E}$ deficiency but this has not been shown consistently in coeliac patients and in patients with other malabsorptive syndromes with deficiency of vitamin E, cerebellar degeneration has tended to be slowly progressive over many years rather than months. ${ }^{4,7}$ In patients with coeliac disease, progression is not halted by vitamin supplementation and neither does it respond to a gluten free diet, suggesting that direct toxicity of gliadin is not implicated. A genetically determined immunological mechanism has been suggested but this is speculative at present and, where cortin costeroids have been tried, this has not met with success. ${ }^{2,3}$ The prognosis at present remains poor but patients with otherwise unexplained cerebellar degeneration should be investigated for malabsorption and coeliac disease even in the absence of abdominal symptoms.

\section{Acknowledgement}

We would like to thank Dr P. Rudge for his encouragement and permission to report on this patient.

\section{References}

1. Cook, W.T. \& Smith, T. Neurological disorders associated with adult coeliac disease. Brain 1966, 89: 683-722.

2. Finelli, P.F., McEntee, W.J., Ambler, M. \& Kestenbaum, D. Adult coeliac disease presenting as cerebellar syndrome. Neurology 1980, 30: 245-249.

3. Kinney, H.C., Burger, P.C., Hurwitz, B.J., Hijmans, J.C. \& Grant, J.P. Degeneration of the central nervous system associated with coeliac disease. J Neurol Sci 1982, 53: 9-22.

4. Ward, M.E., Murphy, J.T. \& Greenberg, G.R. Celiac disease and spinocerebellar degeneration with normal vitamin $E$ status. Neurology 1985, 35: 1199-1201.

5. Kristoferitsch, W. \& Pointer, H. Progressive cerebellar syndrome in adult coeliac disease. $J$ Neurol 1987, 234: 116-118.

6. Brucke, T., Kollegger, H., Schmidbauer, M., Muller, C., Podreka, I. \& Deecke, L. Adult coeliac disease and brain stem encephalitis. J Neurol Neurosurg Psychiatry 1988, 51: 456-457 (letter).

7. Harding, A.E., Muller, D.P.R., Thomas, P.K. \& Willison, H.J Spinocerebellar degeneration secondary to chronic intestinal malabsorption: a vitamin E deficiency syndrome. Ann Neurol 1982, 12: 419-424. 